\title{
Posttransfusion hyperhemolysis syndrome in beta thalassemia major: Postulation of various mechanisms
}

\author{
Ganesh Kasinathan ${ }^{1}$ and Jameela Sathar ${ }^{2}$ \\ ${ }^{1}$ Ampang Hospital \\ ${ }^{2}$ Ampang Hospital.
}

January 30, 2021

\begin{abstract}
Hyperhemolysis syndrome (HS) should be considered in a multiply transfused thalassemia patient. HS in this patient was attributed to a combination of factors including multiple transfusions, presence of anti-Cw, macrophage hyperactivity, hypersplenism and suppression of erythropoiesis.
\end{abstract}

\section{Introduction}

Hyperhemolysis syndrome (HS), a potentially life-threatening condition, was first described in sickle cell disease but was subsequently seen in other hematological conditions such as thalassemia, myelofibrosis and lymphoma ${ }^{1}$. This syndrome is characterised by the occurrence of severe anemia with posttransfusion hemoglobin levels being lower than pretransfusion levels ${ }^{2}$. Intravascular destruction of both host and transfused red blood cells occurs as evident by the presence of positive hemolytic markers such as indirect hyperbilirubinemia, elevated lactate dehydrogenase (LDH), hemoglobinuria, severe reticulocytopenia and decreased serum haptoglobin. HS is categorised into acute and delayed forms. The acute form occurs within the first 7 days of red cell transfusion meanwhile the delayed form occurs more than 7 days post red cell transfusion ${ }^{3}$. HS rarely recurs. Here, we describe the possible mechanisms involved in a transfusion dependent beta thalassemia major patient presenting with acute hyperhemolysis syndrome after red cell transfusion.

\section{Case presentation}

A 45-year-old gentleman of Chinese ethnicity presented to the thalassemia ward with high grade fever associated with black urine, generalised bone pain and worsening jaundice 36 hours after being transfused with 2 units of $\mathrm{ABO}$ and $\mathrm{Rh}$ matched leukoreduced cross match compatible red blood cells. He was a known beta thalassemia major, in which, he underwent regular two-weekly transfusion since childhood. However, he was occasionally non-compliant to his transfusion schedule with the latest blood transfusion being 6weeks prior. He had extramedullary hematopoiesis in the liver, spleen and paraverterbra with mild liver hemosiderosis. He was on dual oral iron chelation therapy. He had a family history of beta thalassemia. He was a non-smoker, a teetotaler and never consumed traditional drugs. He worked as a lawyer.

Physical examination revealed a thin-built gentleman who was significantly pallor and jaundiced. He was febrile at $39.5^{\circ} \mathrm{C}$ with a blood pressure of $140 / 80 \mathrm{mmHg}$ and tachycardic at 112 beats/minute. He did not demonstrate any cutaneous rash. He had a palpable liver of $5 \mathrm{~cm}$ and a spleen of $15 \mathrm{~cm}$. Other systemic examinations were unremarkable.

His pre-transfusion hemoglobin $(\mathrm{Hb})$ of $5.2 \mathrm{~g} / \mathrm{dL}$ decreased further to $4.6 \mathrm{~g} / \mathrm{dL}$ after 2 units of red cell transfusion. He had a steady state mild pancytopenia (total white cell count: $3.2 \times 10^{9} / \mathrm{L}$ and platelet: $75 \times 10^{9} / \mathrm{L}$ ) 
which was attributed to his extramedullary haematopoiesis-related-hypersplenism. His hemolytic markers and peripheral blood film on day 2 of transfusion were consistent with acute intravascular hemolysis. He also had marked hyperferritinemia (his baseline serum ferritin: 200-300 ug/L). His blood and urine cultures were both sterile excluding the possibility of bacterial contamination. The other laboratory parameters are tabulated in Table 1.

Further investigations were performed at the blood bank on Day 2 of transfusion. His ABO and Rh blood grouping on conventional tube technique was $\mathrm{O} R \mathrm{Rh}(\mathrm{D})$ positive, $\mathrm{R} 1 \mathrm{R} 1$ phenotype which were the same previously. The micro Coombs (Direct antiglobulin test-DAT) using low ionic strength saline (LISS)/antihuman globulin (AHG) column agglutination card was $2+$ for anti-C3d and negative for anti-IgG. The antibody screening on patient's serum using ID Diacell Asia I-II-III (LISS/AHG column agglutination card) at $37^{0} \mathrm{C}$ did not demonstrate any unexpected antibodies on Day 2. A repeated micro Coombs test at Day 15 was negative for both anti-IgG and C3d. Furthermore, the antibody screening showed presence of alloantibody in cell III on Day 15 as shown in Table 2. A 11-cell antibody identification panel (Table 3 ) identified anti- $\mathrm{C}^{\mathrm{w}}$ in the patient's serum. The patient's RBCs were genotyped using sequence specific primer-polymerase chain reaction (SSP-PCR) molecular method as $\mathrm{RHCE}^{*} \mathrm{C} / \mathrm{C}, \mathrm{RHD}^{*} 01 / 01, \mathrm{RHCE}$ e/e, $\mathrm{JK}^{*} \mathrm{~A}, \mathrm{JK}^{*} \mathrm{~B}, \mathrm{KEL}^{*} \mathrm{k}, \mathrm{FY}^{*} \mathrm{~A}, \mathrm{GYPA}{ }^{*} \mathrm{~N}, \mathrm{GYPB}^{*}$ s. Hence, the RBC phenotype was predicted as R1R1, C ${ }^{\mathrm{w}}$, Jka+b-, Fya+b-, kk, NN, ss.

A diagnosis of hyperhemolysis syndrome was made. He was treated with a synergistic combination therapy of intravenous methylprednisolone $8 \mathrm{mg} / \mathrm{kg}$ daily and intravenous immunoglobulin (IVIg) at a dose of $0.4 \mathrm{~g} / \mathrm{kg}$ daily for a 5 -day duration. He was also hydrated adequately with isotonic saline, given subcutaneous erythropoietin-alpha and prophylaxis anticoagulation with enoxaparin $40 \mathrm{mg}$ daily (weight $58 \mathrm{~kg}$ ) to prevent hemolysis-induced-thrombosis. The $\mathrm{Hb}$ decreased to a nadir of $3.5 \mathrm{~g} / \mathrm{dL}$ at day 10 before increasing to $5.8 \mathrm{~g} / \mathrm{dL}$ at day 15 without any blood transfusion. He was counselled for splenectomy, in which, he refused for the fear of surgery. He is currently on two weekly crossmatch compatible leukoreduced RBC phenotype matched red blood cell transfusion at our thalassemia daycare center.

Table 1

\begin{tabular}{lllll}
\hline Parameters (normal range in S.I.unit) & Day 2 & Day 6 & Day 10 & Day 15 \\
\hline Haemoglobin $(13.5-16.0 \mathrm{~g} / \mathrm{dL})$ & 4.6 & 4.2 & 3.5 & 5.8 \\
Reticulocyte count $\left(50-100 \times 10^{9} / \mathrm{L}\right)$ & 15.0 & 14.0 & 12.0 & 28.0 \\
Lactate dehydrogenase $(180-250 \mathrm{U} / \mathrm{L})$ & 688 & 522 & 319 & 265 \\
Haptoglobin $(0.3-2.0 \mathrm{~g} / \mathrm{L})$ & 0.0737 & & 0.32 & \\
Indirect Bilirubin $(3.4-12.0 \mathrm{umol} / \mathrm{L})$ & 135 & 94 & & 23 \\
Urine haemoglobin & $2+$ & & 0 & \\
Creatinine $(74-107 \mathrm{umol} / \mathrm{L})$ Ferritin $(24-336 \mathrm{ug} / \mathrm{L})$ & 586700 & & 561550 & \\
\hline
\end{tabular}

Table 1 Haematological and biochemical parameters

Table 2

\begin{tabular}{llll}
\hline Incubation phase & IS & LISS/AHG & CCC \\
\hline Cell I & 0 & 0 & \\
Cell II & 0 & 0 & \\
Cell III & 0 & $1+$ & NT \\
AC & 0 & 0 & \\
\hline
\end{tabular}

Cell followed by a Latin number indicates antibody screening cell; IS: immediate spin; LISS: low ionic strength saline; AHG: anti-human globulin; CCC: Coombs control cells, AC: auto control, NT: not tested 
Table 2 Antibody screening test on Day 15 red cell transfusion

Table 3

\begin{tabular}{|c|c|c|c|c|c|c|c|c|c|c|c|}
\hline Cell No & $\begin{array}{l}\text { Rh-hr } \\
\text { C }^{\text {w }}\end{array}$ & Kell & Duffy & Kidd & Lewis & MNS & $\mathrm{P}$ & Luth. & $\mathrm{Xg}$ & $\begin{array}{l}\text { LISS/ } \\
\text { AHG }\end{array}$ & $\begin{array}{l}\text { Enzyme } \\
\text { (papain) }\end{array}$ \\
\hline Cell 1 & + & & & & & & & & & $2+$ & $4+$ \\
\hline Cell 2 & 0 & & & & & & & & & 0 & $2+$ \\
\hline Cell 3 & 0 & & & & & & & & & 0 & $2+$ \\
\hline Cell 4 & 0 & & & & & & & & & 0 & $2+$ \\
\hline Cell 5 & 0 & & & & & & & & & 0 & $2+$ \\
\hline Cell 6 & 0 & & & & & & & & & 0 & $2+$ \\
\hline Cell 7 & 0 & & & & & & & & & 0 & $2+$ \\
\hline Cell 8 & 0 & & & & & & & & & 0 & $2+$ \\
\hline Cell 9 & 0 & & & & & & & & & 0 & $2+$ \\
\hline Cell 10 & 0 & & & & & & & & & 0 & $2+$ \\
\hline Cell 11 & 0 & & & & & & & & & 0 & $2+$ \\
\hline $\mathrm{AC}$ & & & & & & & & & & 0 & 0 \\
\hline
\end{tabular}

Cell followed by a Latin number indicates antibody screening cell; LISS: low ionic strength saline; AHG: anti-human globulin; CCC: Coombs control cells, AC: auto control, NT: not tested

Table 3 Antibody identification panel on Day 15 red cell transfusion

\section{Discussion}

We describe an unusual presentation of hyperhemolysis in a beta thalassemia major patient who presented with high grade fever, bone pain and malaise. It was interesting to note that Day 2 DAT was negative for anti-IgG but showed $2+$ for anti-C3d. A well performed DAT detects 100-500 molecules of bound IgG per red blood cell. A negative IgG autoantibody is a common feature in acute form of HS. There are several reasons which may explain a negative DAT in HS. They are (a) sensitization of the patient's red cells with a small number of IgG molecules which is below the threshold for detection by a standard DAT (b) most standard DAT do not incorporate anti-IgA monoclonal reagent, thereby, missing out on the possibility of IgA mediated hemolysis (c) low affinity IgG autoantibodies being eluted from RBC during the washing process ${ }^{4}$. A super Coombs test, which incorporates an enhanced and more sensitive version of the standard DAT may be useful in cases where the standard DAT is negative.

It is also interesting to note that the negative anti-C3d on Day 15 repeated DAT in our patient could be attributed to the immunosuppressive corticosteroid therapy given to him.

The pathogenesis of HS is interesting. The mechanisms which may explain HS in our patient are: (a) macrophage hyperactivation (b) RBC alloimmunisation (c) complement regulation dysfunction (d) bystander hemolysis (e) suppression of erythropoiesis and (f) HLA alloimmunisation ${ }^{5}$. Macrophages are widely believed to be in a primed state in hemoglobinopathy syndromes. In response to allogeneic transfusion, macrophages become hyperactivated and bind to both host and donor red blood cells resulting in rapid destruction ${ }^{5}$. Interestingly, our patient had significant extramedullary hematopoiesis in the spleen resulting in hypersplenism. Since the splenic red pulp contains a large number of macrophages, therefore this group of patients are at considerable risk of developing HS.

Bystander hemolysis, a term coined by Petz and Garraty, is used to describe immune hemolysis of erythrocytes in the presence of recipient alloantibodies directed to antigen negative transfused red blood cells ${ }^{6}$. Besides RBC alloantibodies; HLA and plasma protein antigens from the transfused blood may react with the recipient's antibodies contributing to complement regulation dysfunction, thereby leading to bystander 
hemolysis ${ }^{7}$. However, in this patient, we did not perform an HLA antibody screen, and facilities to measure levels of complement factors, C5b-9 to support our findings of complement dysfunction were unavailable.

Besides the above, RBC alloimmunization is also an important cause of hyperhemolysis. A negative antibody screen in our patient at Day 2 of transfusion is a feature commonly seen in the acute form of HS. Standard serological studies used may not be potent enough to detect low affinity alloantibodies against low frequency antigens. Antibody dependent cell mediated cytotoxicity (ADCC) may explain the mechanism of hemolysis in recipients with levels of alloantibody below the serological detection threshold ${ }^{8}$. Interestingly, anti- ${ }^{w}{ }^{w}$ as subsequently detected in our patient's serum on Day 15. This antibody including those of the Kidd or Rh system are often undetectable on pretransfusion testing but may increase rapidly in titer following a blood transfusion. Re-exposure of an antigen negative recipient to a red cell antigen positive transfusion could result in an anamnestic antibody response, precipitating hemolysis. Anti- $\mathrm{C}^{\mathrm{w}}$ is an alloantibody directed against the $\mathrm{C}^{\mathrm{w}}$ antigen ( $\mathrm{Rh} 8$ ), which is located on the RHCE gene. This would explain the initial presence of anti-C3d on Day 2 DAT in which, the anti- $\mathrm{C}^{\mathrm{w}}$ causes activation of the complement. $\mathrm{C}^{\mathrm{w}}$ is a low incidence antigen, and has been reported to be $1 \%$ and $2 \%$ in Blacks and Caucasians respectively ${ }^{9}$. Anti- $\mathrm{C}^{\mathrm{w}}$, usually an IgG antibody, may occur naturally or after an immune stimulation by blood transfusion such as seen in this patient. Unlike other Rh antigens, anti- $\mathrm{C}^{\mathrm{w}}$ is usually not significant. Anti- $\mathrm{C}^{\mathrm{w}}$ associated moderate-to-severe hemolytic disease of the fetus and newborn (HDFN) have been reported infrequently in case reports and thus may be of clinical significance in females of reproductive age ${ }^{10}$. However, literature on the significance of this antibody in acute and delayed hemolytic transfusion reaction is severely lacking.

Severe reticulocytopenia was also an additional feature seen in our patient. Thalassemia patients are known to have significantly lower serum levels of erythropoietin at steady state which may trigger neocytolysis during HS causing further destruction of erythroid precursors ${ }^{11}$. A bone marrow analysis would be helpful to confirm the presence of erythropoiesis suppression. Another mechanism which could also contribute to reticulocytopenia is increased peripheral consumption of reticulocytes by hyperactive macrophages in the presence of preserved bone marrow activity of erythropoiesis.

Management of HS is largely dependent on the severity of anemia and degree of hemolysis. Blood transfusion should be avoided in the milder form of HS as they are known to exacerbate hemolysis. Combination therapy of IVIg and steroids are synergistic in suppressing macrophage activation and shortening hemolysis through immodulatory effects ${ }^{12}$. Low dose IVIg at $0.4 \mathrm{~g} / \mathrm{kg}$ daily for 5 days and intravenous methylprednisolone $500 \mathrm{mg}$ daily for 2 days are recommended for the treatment of $\mathrm{HS}^{12}$. In severe forms of HS, red blood cell transfusion may be required but should be given in the presence of IVIg-steroid cover. Subcutaneous erythropoietin may have a role in direct stimulation of erythropoieis and preventing neocytolysis. Furthermore, since macrophage activation is an important mechanism in HS, anti-CD20 monoclonal antibody such as rituximab $375 \mathrm{mg} / \mathrm{m}^{2}$ even at a single dose has shown response ${ }^{13}$. It is interesting to note that eculizumab, a C5 convertase inhibitor which inhibits complement activation is promising in the treatment of HS in sickle cell anemia and may also confer such benefit in thalassemia ${ }^{14}$. On another note, as hemolysis increases the risk of both arterial and venous thrombosis, it is imperative to ensure adequate anticoagulation prophylaxis is given during active HS. Splenectomy has a role in HS as it is known to resolve HS crisis in thalassemia ${ }^{15}$. However, our patient declined splenectomy due to personal reasons.

\section{Conclusion}

A high index of suspicion of HS allows prompt institution of therapy resulting in good survival outcome. The occurrence of HS in our patient is attributed to a constellation of multiple factors namely; chronic multiple transfusions, presence of anti- $\mathrm{C}^{\mathrm{w}}$, macrophage hyperactivity, extramedullary haematopoiesis-inducedhypersplenism and suppression of erythropoiesis.

\section{Declarations}

Ethical approval: Ethical approval is not required as this is not a clinical trial.

Consent: Written informed consent was obtained from the patient for publication of this case report and the 
accompanying images. A copy of the written consent is available for review by the Editor-in-Chief of this journal on request.

Competing interests: The authors declare there are no conflicting interests.

Funding and sponsorship of this paper: Self-funding and no sponsorship received.

Author's contribution: G.K. analysed the data, designed the paper and wrote the first draft of the manuscript. J.S. made critical revisions and approved the final manuscript.

Guarantor: Ganesh Kasinathan is the guarantor of this manuscript.

Acknowledgements: None

References

1. Gupta S, Fenves A, Nance ST, et al. Hyperhemolysis syndrome in a patient without a hemoglobinopathy, unresponsive to treatment with eculizumab. Transfusion. 2015; 55(3):623-628

2. Win N. Hyperhemolysis syndrome in sickle cell disease. Expert Rev Hematol. 2009; 2(2):111-115.

3. Win N. Blood transfusion therapy for hemoglobinopathies. In: Practical Management of Hemoglobinopathies. Okpala 1 (Ed). Blackwell Publishing. Oxford, UK. 2004; 99-106.

4. Segel G, AL Marshall. Direct antiglobulin (Coombs) test-negative autoimmune hemolytic anemia: A review. Blood cells Mol and Dis. 2014; 52(4):152-60.

5. Uhlmann EJ, Shenoy S, Goodnough LT. Successful treatment of recurrent hyperhemolysis syndrome with immunosuppression and plasma-to-red blood cell exchange transfusion. Transfusion. 2014; 54(2):384-388.

6. Petz LD, Garratty G. Bystander immune hemolysis immune hemolytic anemias ( $2^{\text {nd }}$ edition). Churchill Livingstone, PA, USA. 2004; 358-364.

7. Garratty G. Severe reactions associated with transfusion of patients with sickle cell disease. Transfusion. 1997; 37:357-361.

8. Morawakage LR, Perera BJ, Dias PD, et al. Hyperhemolysis in a patient with beta-thalassemia major. Asian J Transfus Sci. 2009; 3(1):26-27

9. Reid ME, Lomas-Francis C. The blood group antigen: facts book. The blood group system and antigen. San Diego: Academic Press. 2014; 111-112.

10. May-Wewres J, Kaiser JR, Moore EK, et al. Severe neonatal analysis due to maternal antibody to low frequen cy Rh antigen $\mathrm{C}^{\mathrm{w}}$. Am J Perinatol. 2006; 23:213-217.

11. Trial J, rice L. Erythropoietin withdrawal leads to destruction of young red cells at the endothelialmacrophage interface. Curr. Pharmaceut. Design. 2004; 10(2):183-190.

12. Anderson D, Ali K, Blanchette V, et al. Guidelines on the use of intravenous immune globulin for hematologic conditions. Transfusion Med. Rev. 2007; 21:S9-S56.

13. Bachmeyer C, Maury J, parrot A, et al. Rituximab as an effective treatment of hyperhemolysis syndrome in sickle cell anemia. Am J Hematol. 2010; 85:91-2.

14. Dumas G, Habibi A, Onimus T, et al. Eculizumab salvage therapy for delayed hemolysis transfusion reaction in sickle cell disease patients. Blood. 2016; 127(8):1062-1064.

15. Mechery J, Abidogun K, Crosfill F, et al. Hyperhemolysis syndrome complicating pregnancy in homozygous deltabeta thalassemia. Hemoglobin. 2012; 36(2):183-185. 